\title{
Erratum to: Vinpocetine and Vasoactive Intestinal Peptide Attenuate Manganese-Induced Toxicity in NE-4C Cells
}

\author{
Saylav Bora $^{1} \cdot$ Mumin Alper Erdogan $^{1} \cdot$ Güliz Armagan $^{2} \cdot$ Elvin Sevgili $^{2} \cdot$ Taner Dagel $^{1}$
}

Published online: 14 June 2016

(C) Springer Science+Business Media New York 2016

Erratum to: Biol Trace Elem Res (2016)

DOI 10.1007/s12011-016-0742-z

In the above-mentioned article, the author names Mumin Alper Erdogan and Saylav Bora were written incorrectly as Alper Mümin Erdoğan and Ejder Saylav Bora, respectively. However, these errors have been already corrected in both the referenced article and in the author listing for this article. The authors regret the oversight.

The online version of the original article can be found at http://dx.doi.org/ 10.1007/s12011-016-0742-z.

Saylav Bora

saylavbora@hotmail.com

1 Department of Physiology, School of Medicine, Faculty of Medicine, Ege University, 35100 Bornova, Izmir, Turkey

2 Department of Biochemistry, Faculty of Pharmacy, Ege University, 35100 Bornova, Izmir, Turkey 